\title{
A comparison of telehealth programs between the USA and Brazil: a legal perspective
}

This article was published in the following Dove Press journal:

Smart Homecare Technology and TeleHealth

30 November 2015

Number of times this article has been viewed

\section{Lara Rocha Garcia \\ Eliézer Silva \\ José Cláudio Cyrineu Terra}

Hospital Israelita Albert Einstein, São Paulo, São Paulo, Brazil
Correspondence: Lara Rocha Garcia Hospital Israelita Albert Einstein, 627 - Morumbi - São Paulo, São Paulo, Brazil 05652-900

Email Lara.rocha@einstein.br
Abstract: Telehealth has the potential to improve access and outcomes for patients and to reduce health care costs across a wide range of health conditions and situations. The wide adoption of telehealth requires, however, a strong legal and financial foundation. In this article, we compare the evolution of American and Brazilian telehealth legislations and reimbursement schemes. The detailed analysis in this article shows many differences between these two countries that help to explain why telehealth in the USA has a much faster adoption rate than that in Brazil.

Keywords: telemedicine, telehealth, legislation and jurisprudence, consultation, telemedicine in Brazil, barriers of implementation

\section{Introduction}

A key advantage of digital health is mobility. It has a large potential impact on the cost of delivering health care, on the efficiency of the health workforce utilization, and on the timely and equitable access to health care services. ${ }^{1}$ These potential benefits are particularly true in very large countries, such as in the USA and Brazil, where access to health care services is unevenly distributed across their vast territories.

The use of information and communication technology in health care services, more specifically telehealth, can "eliminate" the distance between patients and doctors. It allows data and clinical data sharing, patient's visualization and inspection through high-definition cameras, and real-time collection of vital signs (the measurement of the body's most basic functions). The continuous advances in these types of technologies are allowing the provision of adequate health care, regardless of the location of doctors and patients by bringing the best available knowledge to the point of care, be it a home or a rural hospital.

Although sometimes the terms "telemedicine" and "telehealth" are used as synonyms and used interchangeably, referring to the same context or practice, we will use "telehealth" throughout this article to refer to the broader concept of providing remote health care services even in the absence of clinical services as defined by the Center of Connected Health Policy. ${ }^{2}$

Despite the current very low penetration, many barriers have been overcome, and significant improvements occurred in the application of telehealth in Brazil in the last two decades.

One way of evaluating the degree of said improvement is to compare the current situation of telehealth in Brazil with other more advanced regions of the world, such as the USA. Such comparison could explore many aspects that explain the differences of telehealth in both countries. A very broad comparison could include topics such as 
access to technology, general economics, geographical distribution of medical expertise, the role of private and public health systems, among many others. We had to make some choices in our review strategy. Since this is a highly regulated field at a rather early stage of development, it seemed that understanding the evolution of legislation would provide many useful and practical insights to help policy makers in both countries. Thus, our literature review focused on key widely known pieces of legislation related to telehealth in the USA, Brazil, and International Health and Medical Organizations and a more detailed review of academic articles, particularly from the last 3 years (2012-2014), published in MEDLINE, Law, and Business Resources and nonacademic articles and presentations that address the same topic.

In this review article, we discuss some of the key legal issues and the most important barriers related to the implementation and adoption of telehealth programs by health care workers and patients. To do so, we benchmark the current state of Brazil's telehealth legal framework against the more advanced scenario in the USA.

\section{Evolution of telehealth legislation}

According to our review, the official history of telehealth in the USA started in $1991^{3}$ and in Brazil in $1997 .{ }^{4}$ Since then many changes have occurred in the legislation and in the practice of telehealth in both countries. In Table 1, we have selected critical milestones on the evolution of telehealth in the USA and Brazil. We also highlight some of the key milestones of international medical organizations such as World Health Organization and World Medical Association for context and reference.

The Declaration of Tel Aviv ${ }^{5}$ is the first global regulatory legal framework and the most important initial milestone, supporting the evolution of Telehealth.

The World Medical Association issued the Declaration of Tel Aviv in 1999, in which it recognized telehealth and described some of the key categories (telemonitoring, teleassistance, and teleconsultation). It officially allows the doctor-patient relationship via telehealth as long as it is delivered in such a way as to respect medical ethics, privacy, and confidentiality of information. It is the first document on a global scale to address this subject, strongly suggesting that medical associations apply its principles in their respective countries.

In Brazil, the first juridical fact was a legal opinion of the Federal Council of Medicine about offshore calls in $1997 .{ }^{4}$ However, this was a direct response to Petrobras, a large Brazilian oil company. Other than that, no other Brazilian agency, public or not, issued any opinion or legislation related to telehealth until $2002 .^{6}$

Table I Timeline of major telehealth legislation

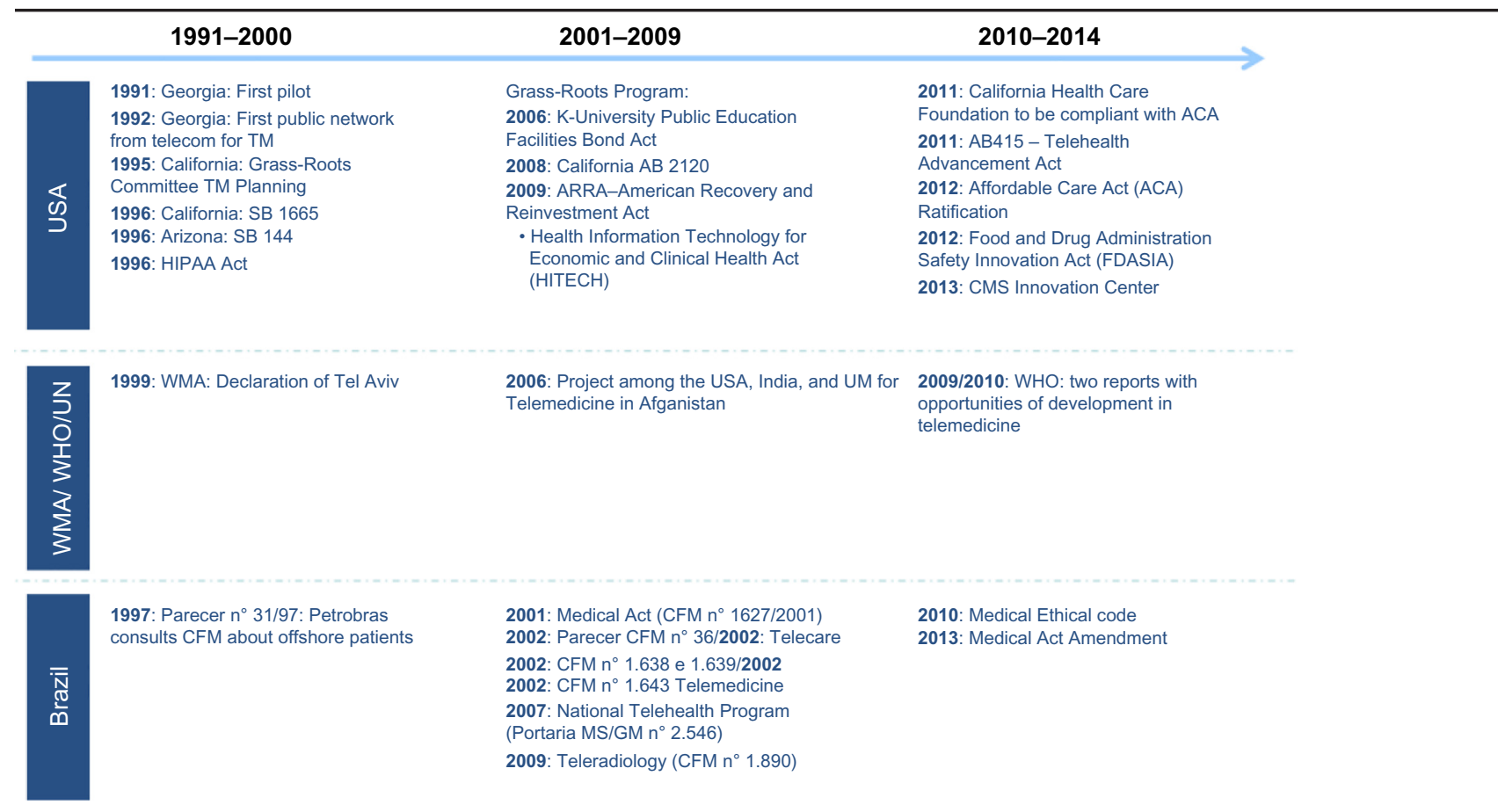

Abbreviations: WMA, World Medical Association; WHO, World Health Organization; UM, University of Miami; TM, telemedicine; HIPAA, Health Insurance Portability and Accountability Act; CFM, Conselho Federal de Medicina. 
The first specific legislation about telehealth was issued 3 years after the Declaration of Tel Aviv, in 2002. Resolution No 1643 of the Federal Council of Medicine made reference to the Declaration of Tel Aviv but fell short in terms of explicitly allowing the doctor-patient relationship through technology. This Brazilian legislation allowed telehealth only when doctors are presented at both ends. Resolution of the Federal Council of Medicine no 1643 is composed of eleven preambles and seven clauses. The main issues addressed in this resolution are the following:

1. A definition of telehealth more streamlined than the one in the Declaration of Tel Aviv but still recognizing possibilities of teaching, research, and assistance

2. Restriction of the relationship only between doctors

3. Exception in case of emergencies, in which it is allowed diagnosis and therapy via telehealth, directly between the doctor and patient

4. Definition of medical responsibility born primarily by the physician assistant but jointly by the remote doctor

5. Definition of medical licensing, whose registration should happen in the state board where he or she is registered.

The main issue for the full development of telehealth in Brazil is related to the doctor-patient relationship. The Medical Federal Council's argument for not fully allowing it entirely through technology is based on the point of view that the required need for a safe bond and trust between the parts cannot happen in this situation. ${ }^{7}$

Following the legal resolution, a few other pieces of legislation were issued related to radiology and psychology, among others, but no new major direction was published beyond these resolutions and ordinances. These two resolutions have two significant differences to the general one (CFM $\left.n^{\circ} 1643 / 2002\right)$ : the first one ${ }^{8}$ permits diagnose and the second ${ }^{9}$ allows doctor-patient relationship.

The analysis of telehealth laws (both at the national and state levels) in the USA ${ }^{10}$ shows that it has evolved following a relatively well-concatenated process ${ }^{11}$ involving six major steps:

1. Use of telehealth in education first initiatives

2. Investment in infrastructure

3. Economic analysis (business case)

4. Targeting at the national level and implementation at the state level

5. Public funding

6. Regulation of public and private reimbursement

In Brazil, although some of the elements and sequence are similar, there are important gaps in interconnection and evaluation of actions, as well as important limitations for practicing and financing of telehealth. In Table 2, we compare some of these milestones as they occurred both in the USA and in Brazil.

Table 2 USA/Brazil comparative telehealth regulation

\begin{tabular}{|c|c|c|c|}
\hline & $1991-2000$ & 2001-2009 & 2010-2014 \\
\hline First pilot & USA & Brazil & \\
\hline Business case & USA & & \\
\hline Infrastructure provider law & USA & Brazil & \\
\hline $\begin{array}{l}\text { Telemedicine regulation } \\
\text { for education }\end{array}$ & USA & Brazil & Brazil \\
\hline General application & WMA & USA & \\
\hline $\begin{array}{l}\text { Security and privace technical } \\
\text { protocol }\end{array}$ & USA & Brazil & \\
\hline National Public Policy & & USA-state level & USA-federal level \\
\hline Publir rimburement for & & & ( \\
\hline $\begin{array}{l}\text { Public reimbursement for } \\
\text { emergency }\end{array}$ & USA & & Brazil \\
\hline $\begin{array}{l}\text { Private reimbursement for } \\
\text { appointment and treatment }\end{array}$ & & USA & \\
\hline Public funding for emergency & & USA & Brazil \\
\hline $\begin{array}{l}\text { Public funding for emergency } \\
\text { appointment and treatment }\end{array}$ & & & USA \\
\hline Devices regulation & & & USA \\
\hline
\end{tabular}

Abbreviation: WMA, World Medical Association. 
Some of the details of these milestones are presented later.

\section{Education}

Many people claim that the telehealth in America is claimed to have begun in 1991 in Georgia. ${ }^{2}$ It was an initiative for medical education proposal led jointly by the Medical College of Georgia and the Dodge County Hospital. This initial successful experience was further expanded to another seven locations in 3 years.

In Brazil, the first-time telehealth was transformed in school discipline in 1997 at University of São Paulo Medical School. In 1999, another public university - Federal University of São Paulo - created its Technology and Telehealth Department. However, the first formal education using telehealth started in 2005, with public national funding, with Rede Universitária de Telemedicina (RUTE) program and Rede Nacional de Ensino e Pesquisa (RNP), which linked many university and public hospitals together. ${ }^{14,24}$

\section{Infrastructure}

Senate Bill 144 from Georgia was proposed in 1992. Its goal was to create a telecommunication network to support distance learning. In the same decade, California creates a committee to study and facilitate telehealth in the state. This committee subsequently established the Grass-Roots Program, ${ }^{2}$ which detailed the basic actions necessary for the development of the program.

In Brazil, there have been several initiatives related to the implementation of infrastructure for supporting telemedicine, but the one that is worth mentioning is Rede Ipê, created in 2005 to support RUTE. ${ }^{12,14,15}$ This program, created by national government, supports national telehealth initiatives since 2006. ${ }^{14}$ RUTE has a peer-to-peer, high speed band backbone infrastructure link named Rede Ipê. It is especially used for educational and communication telehealth programs, to transmit data and video in context of synchronous and asynchronous teleconsultations.

\section{Business case}

This step has the purpose of showing the economic and financial possibilities of telehealth. After the first cases, some leading American universities ${ }^{2}$ started to study the expansion of their pilots, despite the legal, cultural, and technological barriers. They realized that this kind of medicine could be bigger and help in other ways if it could be expanded. For this, they needed to prove the business opportunities to obtain adequate financial resources. Without this milestone, it would not be possible to grow.
The first telehealth pilot of in the USA took place in Georgia in 1991. After 2 years, based on this initial success and a strong business case, the Medical College of Georgia's Telehealth Program was expanded to seven sites. ${ }^{3}$

In Brazil, although it is possible to notice some connections among telemedicine public policies at the federal, state, and municipal levels, the discipline of business case seems absent.

\section{Targeting at the national level and implementation at the state level}

In the middle of the American crisis, in 2009, the American Recovery and Reinvestment Act (ARRA) was launched. It had two objectives: in the short term, to preserve current jobs and creating new ones and in the medium term, to create temporary assistance programs to the most impacted areas by the recession such as infrastructure, education, health, and renewable energy.

A part of ARRA is Health Information Technology for Economic and Clinical Health (HITECH) Act, which launches the national bases for states to build their public health policy.

In 1996, in the state level, California enacted the Senate Bill 1665, which defines key telehealth settings: how it works, the need for written consent of the patient, and the importance of data security. In the same year, the California committee issued a report on the challenges and barriers for the broad adoption of telehealth in the state. The financial issues and possible solutions were a key focus of this report.

At the time of the publication of that report, insurance companies and the state ${ }^{26}$ did not reimburse consultations by phone or any other electronic equipment. The Senate Bill 1665 was the first legal document that formally discusses this challenge and that demands the renegotiation of existing contracts as well as provision for this type of reimbursement for new contracts.

\section{Public funding}

ARRA had an estimated investment in US $\$ 787$ billion $^{16}$ to be distributed in grants for states initiatives in the main areas such as infrastructure, education, health, and renewable energy.

The main goal of ARRA, in broad terms, was to expand benefits for the unemployed and to expand social assistance and economic inclusion. To achieve this, ARRA recognized that all areas should cut costs and recognize technology as a key factor.

Within the parameters of the HITECH Act, telehealth became a tool to reduce costs and expand access to social aid. The use of telehealth in government programs, such as Medicaid and Medicare, was directly related to these goals. ${ }^{27}$ 
In Brazil, the federal government supports the funding of the Telessaúde Program. It received R\$ 80 million $^{28}$ in funding in 2013. At the state and city levels, funding is also provided through multiple funding sources. These funding sources, however, are not consolidated and do not seem to part of a major multilayer and orchestrated scheme.

\section{Regulation of public and private reimbursement}

With the exception of teleradiology, ${ }^{8}$ which services are routinely reimbursed, nonradiology telehealth services payment greatly varies among different countries according to local legislation.

In the USA, for instance, Medicaid reimbursement rules and support for telehealth adoption has been growing steadily over that last few years. However, rules are not uniform across many states in the USA..$^{26,27}$ At present (2015), in 21 states, telehealth has financial parity with traditional face-to-face consultations. ${ }^{10}$

In Brazil, the issue of reimbursements has not yet been addressed by government policies or specific legislation, and there are different financial support schemes for telehealth services. It includes governmental funding for research and clinical practice and reimbursement from insurance companies.

Indeed, some insurance companies have their own telehealth services to monitor patients with chronic conditions. In this case, the objective is to reduce costs related to further clinical events. There are other business models currently in Brazil, including business-to-business one. However, the use of this model is not broadly used.

Table 3 Key differences between telehealth legislation from the USA and Brazil

\begin{tabular}{|c|c|c|}
\hline & USA & Brazil \\
\hline Key issues & $\begin{array}{l}\text { Licencing }^{29} \\
\text { Credentialing and privilages } \\
\text { Responsibility }^{29}\end{array}$ & $\begin{array}{l}\text { Doctor-patient bond }{ }^{14} \\
\text { Medical Ethics Resolution } \\
\text { Medical Act }^{31}\end{array}$ \\
\hline $\begin{array}{r}\text { Categories } \\
\text { permited by law }\end{array}$ & $\begin{array}{l}\text { Education }^{17} \\
\text { Store and forward }{ }^{17} \\
\text { Emergency }^{17} \\
\text { eVisit (real time) }^{17} \\
\text { Specialities (specific medical protocols) }{ }^{17}\end{array}$ & $\begin{array}{l}\text { Education }^{6} \\
\text { Store and forward } \\
\text { Emergency }^{6}\end{array}$ \\
\hline $\begin{array}{l}\text { Permitted } \\
\text { relationship }\end{array}$ & $\begin{array}{l}\text { Doctor-doctor }{ }^{17} \\
\text { Doctor-patient (eVisit) }{ }^{17} \\
\text { Doctor-patient (diagnose) })^{17} \\
\text { Doctor-patient (drugs prescription) })^{17} \\
\text { Doctor-patient (treatment) }{ }^{17}\end{array}$ & $\begin{array}{l}\text { Doctor-doctor }^{6} \\
\text { Doctor-multiprofessional team } \\
\text { (emergency) }^{6} \\
\text { Doctor-patient (emergency) } \\
{ }^{6} \\
\text { Doctor-patient (telemonitoring and } \\
\text { teleassistance) }{ }^{6}\end{array}$ \\
\hline $\begin{array}{l}\text { Medical civil } \\
\text { responsibility }\end{array}$ & Individual state legislation ${ }^{26,27}$ & $\begin{array}{l}\text { By consumer code (objective and } \\
\text { subjective responsibility) }{ }^{32,33}\end{array}$ \\
\hline Consent & $\begin{array}{l}\text { Informed Consent Form. In some states, } \\
\text { can be oral consent }{ }^{26,27}\end{array}$ & $\begin{array}{l}\text { Written and formal Informed Consent } \\
\text { Form. Emergency is free }{ }^{6}\end{array}$ \\
\hline Devices rules & FDA Safety Innovation Act ${ }^{22}$ & $\begin{array}{l}\text { No regulation curently by the ANVISA } \\
\text { (Brazilian Health Surveillance Agency) }\end{array}$ \\
\hline $\begin{array}{r}\text { Multidisciplinary } \\
\text { team }\end{array}$ & $\begin{array}{l}\text { There is no current regulation demanding } \\
\text { that every decision should be taken by a } \\
\text { doctor }\end{array}$ & $\begin{array}{l}\text { Although the Medical } \text { Act }^{30} \text { and Medical } \\
\text { Ethics Resolution }{ }^{30} \text { have been slowly } \\
\text { changing, there are still lots of restrictions }\end{array}$ \\
\hline Diagnostics & $\begin{array}{l}\text { In the states that permits the eVisit, there is } \\
\text { no restriction } 16,17,20,26,27\end{array}$ & $\begin{array}{l}\text { Only for radiology. The remote doctor can } \\
\text { refuse to diagnose if it is not clear. It cannot } \\
\text { be directly given to the patient, only for } \\
\text { another doctor }\end{array}$ \\
\hline Drugs prescription & $\begin{array}{l}\text { In the states that permit the eVisit, there is } \\
\text { no restriction }{ }^{16,17,20,26,27}\end{array}$ & Not permitted ${ }^{6}$ \\
\hline
\end{tabular}


One model is through collaborations of top private hospitals with the Public Health Sector, to multiply medical excellence and collaborate with the National Healthcare System (PROADI-SUS). For instance, since May 2012, a tele-ICU program was established by the Hospital Israelita Albert Einstein in partnership with the Brazilian Health Ministry. Through this partnership telemedicine has been implemented at several hospitals in different Brazilian regions with the aim to reduce mortality rate associated with sepsis, acute myocardial infarction, and stroke. This program was financed through a waived taxes program available for leading notfor-profit institutions.

\section{Summary of comparison between USA and Brazilian telehealth legislation}

Although both American and Brazilian legislation were initially developed following the Declaration of Tel Aviv, their current status is very far apart. Table 3 highlights their main differences.

The discussions and examples of the preceding parts of this article show that, in the USA, legal issues pursue a wellstructured framework. In Brazil, legislation has evolved very little in the last 2 decades, does not have a solid framework, and still does not provide a solid basis for the development of telemedicine.

\section{Discussion}

In telehealth, doctors and health care workers, in general, become facilitators with highly specialized medical knowledge conducting the health process, while patients become managers of their health. This more pro active attitude required from patients, particularly in the case of chronic ones, can often become a challenge for the full exploitation of the benefits of telehealth.

This rather new and disruptive telehealth scenario has emerged in the last 2 decades in some pioneering countries or in just the last few years in most countries. During this timeframe, we have seen many advances in technology and communication capabilities. Medical practice is also adapting through trial and errors, pilot studies, clinical tests, and research. Adequate and supportive legislation and financial models (funding and reimbursement), however, seem to be lagging behind. In the case of Brazil, this gap is probably the greatest impediment for the rapid adoption of many telehealth solutions. Thus, the motivation to write this article was to provide a detailed understanding of such gap in Brazil, using the USA experience as a benchmark.
The most important potential advantages of telehealth are the following: ${ }^{34}$

- High-quality service to a larger number of patients

- Standardization of care through centralization of expertise and protocols

- Platform that allows several players to collaborate and provide integrated care by sharing patient data to all parties involved in providing the best treating for patients

Telehealth, however, still has a long path to have a significant impact in Brazil and many other countries. As the history of telehealth and evolution of current legislation has shown, much remains to be done. It could be argued that one of the most fundamental things to accelerate telehealth expansion in Brazil would be to develop strong legal standards. Well-developed legal standards reduce uncertainty and provide many benefits, including security for use of technology, regulation for public and private reimbursement, provision of a legal environment for doctor-patient trustful bond, acceleration of the processes for devices regulations, and innovation within legal boundaries.

The legal standards neither solve all the problems nor eliminate all the barriers but can be a strong foundation to foster telehealth in Brazil, aligning stakeholders' interests, providing a new and strong pathway to improve health care. The comparison with the evolution of the USA legislation does not provide a detailed blueprint since the health system and economic conditions of these two countries are quite different. Brazil, however, must try to learn as much as it can from not only the USA path but from any other country where telehealth has progressed more rapidly.

The legal and financial issues may be the cornerstones of a broad telehealth policy; however, the ultimate issue to be addressed is the doctor-patient relationships supported by electronic means of communication. There are many legitimate concerns, including security and privacy issues, the incidence of responsibility, the respect for medical ethics, and the use of the best evidence available for diagnosis and treatment. As discussed earlier, telehealth is still at an early stage. Thus, all these issues and accompanying legislation are bound to be examined and reviewed often in the near future.

While several telehealth proponents do believe that this kind of service brings the best standard of care for people with no access to it, there are several opponents that do believe that it represents a break in the traditional doctor-patient relationship, inflicting both ethical and legal rules.

Many opponents also argue that the use of telehealth could be unsafe to patients and that there is no enough 
evidence to use it. Moreover, the resistance to adopt telehealth could also be a human behavior or a behavior change issue. Indeed, there are a lot of information how fast physicians adopt new technologies. In general, they are more conservative about their clinical practice and demand legal support and patient's acceptance before adopting new technology.

At the heart of these opponents' reservations regarding telehealth is their perception that the guidelines, standards, and regulations that are needed to ensure telehealth is practiced legally and ethically in several different scenarios whether they be feasibility studies or, more worryingly, fully operational services that have been integrated into mainstream practice by a health care institution - are presently either inadequate or nonexistent.

Are these arguments simply an exaggeration or have the legal and human rights of the patient, who is, after all, intended to be the principal and fundamental beneficiary of the health telematics revolution - genuinely been subordinated to technological progress or improved costeffectiveness?

\section{Disclosure}

The authors report no conflicts of interest in this work.

\section{References}

1. Wade et al. BMC Health Services Research 2010;10:233.

2. California Telemedicine and Health Center. Optimizing Telehealth in California: An Agenda for Today and Tomorrow. Sacramento, CA: California Telemedicine and eHealth Center; 2009:1-21.

3. KATZ-BELL, Jana. Creating Collaborative Initiatives: Proceedings at American Telemedicine Association Conference, Austin, Texas; May, 2013.

4. Parecer do Conselho Federal de Medicina Brasileiro. [Brazilian Federal Medical Council Legal Opinion] n. 31/1997. Portuguese.

5. World Medical Association. WMA Statement on Accountability, Responsabilities and Ethical Guidelines in The Pratice of Telemedicine. Adopted by the 51st World Medical Assembly, Tel Aviv, Israel, 1999. Ferney-Voltaire: World Medical Association:1-6.

6. Resolução do Conselho Federal de Medicina Brasileiro [Brazilian Federal Medical Council Resolution] n ${ }^{\circ}$ 1.643/2002. Portuguese.

7. Rezende EJC, Melo MCB, Tavares EC, Santos AF, Souza C. Ética e Telessaúde: reflexões para uma prática segura.[Ethics and Telehealth: thoughts for a safe pratice]. Rev Panam Salud Publica. Portuguese.2010;28(1):58-65.
8. Resolução do Conselho Federal de Medicina [Brazilian Federal Medical Council Resolution] n ${ }^{\circ}$ 1890/2009. Portuguese.

9. Resolução do Conselho Federal de Psicologia [Brazilian Federal Psycology Council Resolution] $n^{\circ} 003 / 2000$ and $n^{\circ} 006 / 2000$. Portuguese.

10. Castro D, Miller B, Nager A. Unlocking the Potential of Physician-toPatient Telehealth Services. Washington, DC: The Information Technology and Innovation Foundation. 2014:1-21.

11. Stapic Z, Vreck N, Hajdin G. Legislative Framework for Telemedicine. Zagreb: University of Zagreb; 2014.

12. Portaria do Ministério da Saúde [Health Ministry Resolution] no 561 1.228 - 7 - 3.275 / 2006. Portuguese.

13. Georgia Senate Bill n. 144/1992.

14. Messina LA, Simões N, Araújo G, et al. A Rede Universitária de Telemedicina - RUTE. In: Gold Book Inovação Tecnológica em Educação e Saúde. 2012:56-85.

15. Portaria do Ministério da Saúde Brasileiro [Health Ministry Resolution] $\mathrm{n}^{\circ} 2.546 / 2011$. Portuguese.

16. American Reinvestment Recovery Act (ARRA) 2009.

17. Health Information Technology for Economic and Clinical Health Act (HITECH); 2009.

18. Health Insurance Portability and Accountability Act (HIPAA) 1996.

19. Resolução do Conselho Federal de Medicina Brasileira [Brazilian Federal Medical Council Resolution] n ${ }^{\circ}$ 1.821/2007. Portuguese.

20. Affordable Care Act (ACA) 2010

21. Portaria SE do Ministério da Saúde n. 611/2011 (PROADI).

22. Food and Drugs Administration Safety Innovation Act (FDASIA) 2012.

23. Cortez NG, Cohen Glenn, Kesselheim AS. FDA Regulation of Mobile Health Technologies. N Eng J Med; 2014:371-379.

24. Portal da Telemedicina. [homepage on the Internet]. Available from: http://telemedicina.fm.usp.br/portal/telemedicina-no-brasil/. Accessed May 1, 2015.

25. Rede Universitária de Telemedicina. [homepage on the Internet]. O que é a Rede Universitária de Telemedicina (Rute)? Available from: http:// rute.rnp.br/arute;jsessionid=5E36D5DF046C450F203C4D868FEB2D 1E.inst2. Accessed May 1, 2015.

26. State Telehealth Laws and Reimbursement Policies, 2013.

27. State Telemedicine Legislation Tracking [homepage on the Internet]. Washington, DC: American Telemedicine Association; 2014. http://www. americantelemed.org/docs/default-source/policy/state-telemedicinelegislation-matrix.pdf?sfvrsn=102. Accessed Sep 2014.

28. Portal da Telemedicina. [Telemedicine Website] [homepage on the Internet]. Available from: http://telemedicina.fm.usp.br/portal/telemedicinano-brasil/. Accessed May 1, 2015.

29. University of Maryland School of Law. Law and Health Care Program. Legal impediments to the diffusion of telemedicine. J Health Care Law Policy. 2011;14:1.

30. Código de Ética Médica Brasileiro [Code of Medical Ethics] Resolução do Conselho Federal de Medicina Brasileiro [Federal Medical Council Resolution] n ${ }^{\circ}$ 1.931/2009. Portuguese.

31. Ato Médico - Projeto de Lei do Senado Federal n. 268/2002.

32. Código de Defesa do Consumidor - Brazilian Consumer Code.

33. Código Civil Brasileiro - Brazilian Civilian Code.

34. Ministério da Saúde. Estratégia e-saúde para o Brasil do. Brasília: Ministério da Saúde. Available from: http://cspace.eportuguese.org/ tiki-download_file.php?fileId=1173. Accessed May 25, 2015.

\section{Publish your work in this journal}

Smart Homecare Technology and TeleHealth is an international, peer-reviewed, open access online journal publishing original research, reviews, editorials and commentaries on the application of technology to support people and patients at home and in assisted living centers to optimize healthcare and management resources. Specific topics in the journal include: Development and application of

\section{Dovepress}

devices within the home and embedded in appliances; Healthcare provider communication and education tools; and drug ordering and adherence. The manuscript management system is completely online and includes a very quick and fair peer-review system, which is all easy to use. Visit http://www.dovepress.com/ testimonials.php to read real quotes from published authors. 